\title{
Comunicação
}

[Communication]

\section{Freqüência de parasitas intestinais em felinos mantidos em zoológicos}

\author{
[Frequency of intestinal parasites in felines kept in zoos] \\ G.C.K. Müller ${ }^{1}$, J.A. Greinert ${ }^{2 *}$, H.H. Silva Filho ${ }^{2}$ \\ ${ }^{1}$ Aluna de Graduação em Biologia- FURB \\ ${ }^{2}$ Departamento de Ciências Naturais - Universidade Regional de Blumenau \\ Rua Antonio da Veiga, 140 - Bairro Victor Konder \\ 89010 - 971 - Blumenau, SC
}

O cativeiro de animais induz ao estresse, diminuindo a capacidade imunológica e propiciando o surgimento das parasitoses. As infecções parasitárias são intimamente relacionadas aos alimentos e hábitos dos animais. A maioria das infecções parasitárias intestinais é assintomática, geralmente os animais jovens são mais freqüentemente e severamente parasitados (Birchard e Sherding, 1998). As contínuas modificações ambientais favorecem a disseminação de doenças, particularmente aquelas transmitidas por vetores (Rey, 2001). Diversos trabalhos relatam infecções parasitárias observadas em animais mantidos em cativeiros, dentre eles, lobos-guará (Gilioni e Silva, 1999), primatas e herbívoros (Gracenea et al., 2002). As possíveis fontes de infecção nos zoológicos são roedores nativos, pássaros silvestres que têm acesso ao cativeiro e resíduos nos pés dos tratadores (Davis e Wray, 1997). O objetivo do presente trabalho foi estudar a freqüência de infecções parasitárias em animais de cativeiro em dois zoológicos.

Foram analisadas fezes de 18 felinos confinados em dois zoológicos: Zoológico Municipal de Pomerode - SC (13 indivíduos) e Fundação Parque Ecológico Zoobotânico de Brusque - SC (cinco). Neles não existia programa de vermifugação dos animais investigados. A coleta das fezes foi feita semanalmente, no período da manhã, em frascos plásticos descartáveis contendo conservante SAF. As amostras foram analisadas no laboratório de imunologia e parasitologia da Universidade Regional de Blumenau. A pesquisa e a identificação dos parasitas foram realizadas por meio de três diferentes métodos: método de Faust e colaboradores, método de Baermann e método de sedimentação simples, conforme Hoffmann (1987).

Após o exame parasitológico de 84 amostras de fezes de 13 animais, provenientes do Zoológico Municipal de Pomerode, observou-se contaminação em 17 (20,2\%), correspondendo à freqüência de $6(46 \%)$ animais infectados. Na Fundação Parque Ecológico Zoobotânico de Brusque, cinco animais estavam parasitados e, em relação às 28 amostras fecais coletadas, 18 $(64,3 \%)$ delas apresentavam contaminação com uma ou mais espécies de protozoário e/ou helminto (Tab. 1).

Segundo Birchard e Sherding (1998), as trichuriases (Trichuris serrata e T. campanula) ocorrem pela ingestão de ovos infectantes. O ciclo vital é direto, e o período pré-patente de, aproximadamente, três meses. Os ovos podem sobreviver e permanecer no ambiente por até um ano, assim, o solo é o principal fator da contaminação. Existe grande dificuldade de erradicar o parasita do solo infectado, e a reinfecção freqüente constitui um problema comum. A freqüência de animais do Zoológico de Pomerode infectados com Trichuris spp. foi

Recebido para publicação em 17 de dezembro de 2003

Recebido para publicação, após modificações, em 4 de agosto de 2004

* Autor para correspondência (corresponding author)

E-mail: juliane@furb.br 
de $30,7 \%$ e incluiu Panthera onça (pintada e melânica) e Puma concolor. Foi observada infecção por Giardia spp. em 38,5\% dos animais, sendo $23,1 \%$ deles também parasitados por
Trichuris spp. No Parque Ecológico Zoobotânico de Brusque, um animal (Phantera onça) estava infectado por Trichuris spp (Tab. 1).

Tabela 1. Freqüência de parasitas em fezes de felinos mantidos em zoológicos

\begin{tabular}{|c|c|c|c|c|c|c|}
\hline \multirow{2}{*}{ Animal } & \multirow{2}{*}{$\begin{array}{l}\text { No. de } \\
\text { animais }\end{array}$} & \multicolumn{2}{|c|}{ No. de amostras } & \multicolumn{3}{|c|}{ Parasitas } \\
\hline & & Coletadas & Positivas & Giardia & Toxocara & Trichuris \\
\hline & \multicolumn{6}{|c|}{ Zoológico de Pomerode - SC } \\
\hline Panthera tigris $(\mathrm{M} / \mathrm{F})$ & 2 & 8 & - & - & - & - \\
\hline Panthera tigris $(\mathrm{F})$ & 1 & 11 & - & - & - & - \\
\hline Panthera leo (M/F) & 2 & 9 & - & - & - & - \\
\hline Panthera onça $(\mathrm{M} / \mathrm{F})$ (pintada) & 2 & 10 & $7(70 \%)$ & $3(30 \%)$ & - & $4(40 \%)$ \\
\hline Panthera onça (M) (melânica) & 1 & 12 & $3(25 \%)$ & - & - & $3(25 \%)$ \\
\hline Puma concolor (M) & 1 & 11 & $5(45,5 \%)$ & $4(36,4 \%)$ & - & $1(9,1 \%)$ \\
\hline Leopardus tigrinus $(\mathrm{M} / \mathrm{F})$ & 2 & 12 & $2(16,7 \%)$ & $2(16,7 \%)$ & - & - \\
\hline \multirow[t]{2}{*}{ Leopardus wiedii (M/F) } & 2 & 11 & - & - & - & - \\
\hline & \multicolumn{6}{|c|}{ Fundação Parque Ecológico Zoobotânico de Brusque - SC } \\
\hline Felis serval (M/F) & 2 & 13 & $12(92,3 \%)$ & - & $12(92,3 \%)$ & - \\
\hline Panthera onça $(\mathrm{F})$ & 1 & 7 & $2(28,6 \%)$ & - & - & $2(28,6 \%)$ \\
\hline Leopardus wiedii $(\mathrm{M} / \mathrm{F})$ & 2 & 8 & $4(50 \%)$ & $3(37,7 \%)$ & $1(12,5 \%)$ & - \\
\hline
\end{tabular}

Os ovos de Toxocara spp. permanecem viáveis durante meses, ou mesmo anos, sob condições apropriadas de temperatura, umidade $\mathrm{e}$ luminosidade. As formas tissulares desses parasitos podem permanecer latentes ao longo de toda a vida de seus respectivos hospedeiros intermediários (Chandler et al., 1988). Nos animais do Zoológico de Pomerode, não foi observada infecção por Toxocara spp. No Parque Ecológico Zoobotânico de Brusque, $80 \%$ dos animais (Felis serval e Leopardus wiedii) estavam infectados com Toxocara spp., sendo que $40 \%$ também apresentavam Giardia spp.

Um aspecto relevante dos parasitas de felinos, tanto endoparasitas como ectoparasitas, é o problema que representam como zoonoses, podendo oferecer risco de contaminação às pessoas que entram em contato com esses animais (Chandler et al., 1988).
Segundo Dryden (1996), a ocorrência de doenças parasitárias nos felinos pode estar ligada à alimentação, como ingestão de hospedeiros intermediários contaminados, ingestão de água contaminada, disseminação de parasitas pelos tratadores, contaminação por outros animais e, até mesmo, ocupação anterior do recinto por outro animal.

A elevada freqüência de parasitoses intestinais ressalta a necessidade da implantação de medidas de controle, na tentativa de melhorar as condições de vida dos animais e evitar a disseminação para outros recintos dos zoológicos investigados.

Palavras-chave: felino, zoológico, cativeiro, parasitas intestinais

\section{ABSTRACT}

The endoparasites occurrence in felines confined in two Zoos, between December 1999 and April 2000, was studied. Fecal samples of 18 felines (Panthera tigris, Panthera leo, Felis serval, Panthera onca, Puma concolor, Leopardus tigrinus and Leopardus wiedii) were collected and the methods of Faust, modified Baermann and Hoffmann, were used for fecal analyses. Three genera were identified in the feces: Trichuris spp., Toxocara spp. and Giardia spp. In the zoo of Pomerode, six animals (46\%) were infected 
by Trichuris spp. and/or Giardia spp. and all samples from the zoo of Brusque were infected by Trichuris spp., Toxocara spp. and Giardia spp.

Keywords: feline, zoo, captivity, intestinal parasites

\section{REFERÊNCIAS BIBLIOGRÁFICAS}

BIRCHARD, S.J.; SHERDING, R.G. Manual Saunders: clínica de pequenos animais. São Paulo: Roca, 1998.

CHANDLER, E.A.; HILBERY, A.D.R.; GASKELL, C.J. Medicina e terapêutica de felinos. São Paulo: Manole, 1988.

DAVIES, R.H.; WRAY, C. Distribution of Salmonella contamination in ten animal feedmills. Vet. Microbiol., v.51, p.159-169, 1997.

DRYDEN, M.W. Diagnosis and control of gastrointestinal parasites in dogs and cats. Vet. Q., v.18, suppl. 1, p.542-543, 1996.
GILIOLI, R.; SILVA, F.A. Frequency of parasites and Salmonella infection in captive maned-wolf, Chrysocyon brachyurus, kept in zoos at the State of São Paulo, Brasil. Arq. Bras. Med. Vet. Zootec., v.52, p.33-37, 2000.

GRACENEA, M.; COMÉZ, M.S.; TORRES, J. et al. Transmission dynamics of Cryptosporidium in primates and herbivores at the Barcelona zoo: a longterm study. Vet. Parasitol., v.104, p.19-26, 2002.

HOFFMANN, R.P. Diagnóstico de parasitismo veterinário. Porto Alegre: Sulina, 1987.

REY, L. Parasitologia. 3.ed. Rio de Janeiro: Guanabara Koogan, 2001. 